\title{
Dendritic Cell-Associated Immune Inflammation of Cardiac Mucosa: A Possible Factor in the Formation of Barrett's Esophagus
}

\author{
Yuri V. Bobryshev • Dinh Tran • \\ Murray C. Killingsworth • Michael Buckland • \\ Reginald V. N. Lord
}

Received: 22 September 2008 / Accepted: 28 October 2008 / Published online: 18 November 2008

(C) The Author(s) 2008. This article is published with open access at Springerlink.com

\begin{abstract}
Background The development of Barrett's esophagus is poorly understood, but it has been suggested that cardiac mucosa is a precursor of intestinal type metaplasia and that inflammation of cardiac mucosa may play a role in the formation of Barrett's esophagus. The present study was undertaken to examine the presence and distribution of immune-inflammatory cells in cardiac mucosa, specifically focusing on dendritic cells because of their importance as regulators of immune reactions.

Material and Methods Endoscopic biopsy specimens were obtained from 12 patients with cardiac mucosa without Barrett's esophagus or adenocarcinoma and from 21 patients with Barrett's esophagus without dysplasia (intestinal metaplasia). According to histology, in nine of the 21 specimens with Barrett's esophagus, areas of mucosa composed of cardiac type epithelium-lined glands were present as well. Immunohistochemical staining and electron microscopy were used to examine immune-inflammatory cells in paraffin-embedded sections.

Results Immune-inflammatory cells, including T cells, B cells, dendritic cells, macrophages, and mast cells, were present in the connective tissue matrix that surrounded cardiac type epithelium-lined glands in all patients with cardiac mucosa. Clustering of dendritic cells with each other and with lymphocytes and the intrusion of dendritic cells between glandular mucus cells were observed. In the Barrett's esophagus specimens that contained cardiac type glands, computerized CD83 expression quantitation revealed that there were more dendritic cells in cardiac mucosa than in intestinal metaplasia.

Conclusion Immune-inflammatory infiltrates containing dendritic cells are consistently present in cardiac mucosa. The finding of a larger number of dendritic cells in areas of cardiac mucosa in Barrett's esophagus biopsies suggests that the immune inflammation of cardiac mucosa might play a role in modifying the local tissue environment to promote the development of specialized intestinal type metaplasia.
\end{abstract}

Funding The research was supported by the National Health and Medical Research Council, Cancer Institute NSW, NSW Cancer Council, and St. Vincent's Clinic Foundation, Sydney.

Y. V. Bobryshev $\cdot$ R. V. N. Lord

Department of Surgery and Centre for Immunology,

St. Vincent's Hospital, University of New South Wales,

Sydney, Australia

Y. V. Bobryshev ( $\square)$

Faculty of Medicine, University of New South Wales,

Kensington, NSW 2052, Australia

e-mail: y.bobryshev@unsw.edu.au

D. Tran • M. Buckland

Division of Anatomical Pathology, St. Vincent's Hospital,

Sydney, Australia
M. C. Killingsworth

Department of Anatomical Pathology,

South Western Area Pathology Service,

Liverpool, NSW 2170, Australia

R. V. N. Lord $(\bowtie)$

Department of Surgery and Centre for Immunology,

St. Vincent's Hospital,

Darlinghurst, NSW 2010, Australia

e-mail: rvlord@stvincents.com.au 
Keywords Cardiac Mucosa · Barrett's esophagus . Intestinal metaplasia $\cdot$ Dendritic cells $\cdot$ Inflammation

\section{Introduction}

Cardiac mucosa is a type of mucosa that is lined by simple mucinous columnar epithelium with no parietal cells or chief cells, and this distinguishes cardiac mucosa from gastric oxyntic mucosa. ${ }^{1-3}$ In the past, it was believed that up to $2 \mathrm{~cm}$ of cardiac mucosa was normally present in the most proximal section of the stomach where it separates the parietal and chief cell-containing gastric oxyntic mucosa from the esophageal mucosa lined by squamous-stratified epithelium (squamous mucosa). ${ }^{1-4}$ This prevailing view was challenged by studies suggesting that cardiac mucosa, rather than being a normally occurring mucosa, might be an acquired, metaplastic epithelium that develops in response to exposure of esophageal squamous epithelium to gastric acid. $^{2}$ According to this hypothesis, at the normal gastroesophageal junction, squamous mucosa transitions directly with oxyntic mucosa of the gastric fundus with no interposed segment of cardiac mucosa. ${ }^{2}$ An examination of the gastroesophageal junction in a large number of autopsies of subjects, the medical records of whom had no mention of gastroesophageal reflux disease, has revealed that, in most children and adults younger than 20 years of age, the squamous mucosa of the distal esophagus transitioned directly with the oxyntic mucosa of the gastric fundus with no interposed segment of cardiac type simple columnar epithelium. ${ }^{5}$ Further observations suggested that the development of cardiac mucosa is induced by exposing squamous epithelium to refluxed gastric acid. ${ }^{2,6-8}$ This introduced the possibility that the formation of cardiac mucosa may be the first step in the development of Barrett's esophagus, ${ }^{1,2,5,6}$ although controversy regarding the nature and etiology of cardiac mucosa remains. Unfortunately, limitations as to the accurate location of endoscopic biopsies ${ }^{1,3,6}$ and the rapid autolysis of the mucosa of the gastroesophageal junction in autopsy specimens ${ }^{1,5}$ have made it difficult to resolve this controversy.

It is thought that the primary importance of cardiac mucosa is that it represents the only mucosal type that can progress to specialized intestinal type metaplasia. ${ }^{1,2}$ Once intestinalized, the esophagus seems to acquire an increased ability to withstand damage by refluxed gastric juice, compared with cardiac mucosa. ${ }^{1,2}$ However, the development of specialized intestinal type of metaplasia (Barrett's esophagus) can also be a detrimental change because specialized intestinal type epithelium is capable of further progression to epithelial dysplasia and adenocarcinoma. ${ }^{1-8}$ Available evidence suggests that cardiac mucosa itself is benign and that it is only with the development of intestinal type metaplasia the mucosa becomes premalignant. ${ }^{1,2}$

It is established that premalignant conditions develop in the presence of chronic inflammation and that immune mechanisms are critically involved in the development of cancer in these precancerous tissues. ${ }^{9-11}$ A variety of inflammatory and immune cells populate the Barrett's esophagus mucosa, including $\mathrm{T}$ and $\mathrm{B}$ lymphocytes, mast cells, and macrophages. ${ }^{12-14}$ We recently reported that antigen-presenting dendritic cells are present in Barrett's esophagus with a significant increase in their spatial density in adenocarcinoma compared to benign Barrett's esophagus. ${ }^{14}$ Dendritic cells are powerful initiators and regulators of immune reactions ${ }^{15-19}$ and thus may have a role in the pathogenesis of Barrett's esophagus and adenocarcinoma. ${ }^{14}$

In contrast to Barrett's esophagus, cardiac mucosa has received only very limited attention, possibly because it is not associated with an increased risk of cancer. ${ }^{1,2}$ Nevertheless, it has been noted that inflammatory cells are so routinely present in cardiac mucosa biopsies that an alternative term for cardiac mucosa is "carditis." related to either Helicobacter pylori infection or other gastric mucosal pathology. ${ }^{2}$ This prominent inflammatory infiltrate led to the suggestion that it may play a role in the formation of Barrett's esophagus, but there have been no detailed studies in this area. ${ }^{2,4}$ We undertook this study to examine the immune-inflammatory cells, especially the presence, distribution, and cell interactions of dendritic cells, in cardiac mucosa.

\section{Material and Methods}

\section{Tissue Specimens and Routine Histology}

Endoscopic biopsy specimens selected for the present study were obtained from 12 patients without Barrett's esophagus or adenocarcinoma and from 21 patients with Barrett's esophagus without dysplasia. The specimens were taken from the tubular esophagus above the proximal extent of the gastric rugal folds from varying areas of the columnarlined segment. The length of the columnar-lined esophagus varied from approximately $1 \mathrm{~cm}$ to approximately $4 \mathrm{~cm}$. Tissue specimens were defined as Barrett's esophagus when specialized intestinal type columnar epithelium containing true goblet cells (specialized intestinal metaplasia) was present in any length of the columnar-lined esophagus. Cardiac mucosa was diagnosed by the presence of columnar epithelium consisting of mucous cells without any specialized cells such as parietal, chief, or goblet cells. Histological examination demonstrated that amongst 21 biopsy specimens with Barrett's esophagus, cardiac type glands were also present in nine specimens, while no 
gastric (oxyntic) type epithelium was detected in any specimen. Only intestinal metaplasia was present in the other 12 specimens. Tissue specimens were processed by standard formalin fixation and paraffin embedding.

Material was collected in accordance with the principles outlined in the Declaration of Helsinki and informed, written consent was obtained from each patient. The study was approved by the Institutional Review Board of St. Vincent's Hospital, Sydney and the University of New South Wales, Sydney.

Single and Double Immunostaining Procedures and Quantitative Analysis

Dendritic cells were identified using anti-CD83 (Immunotech; cat. no. IM-2069; 1:50 dilution) and anti-DC-SIGN (Santa Cruz; cat. no. sc-65892; 1:50 dilution). CD83, an inducible glycoprotein belonging to the immunoglobulin superfamily, is important in T cell immunity mediated by dendritic cells. ${ }^{20-24}$ CD83 is the most specific dendritic cell marker expressed by maturing and mature dendritic cells. ${ }^{21-24}$ DC-SIGN is dendritic cell-specific intercellular molecule-3 (ICAM-3)grabbing nonintegrin. ${ }^{25,26} \mathrm{~T}$ cells were identified using antiCD3 (Dako; cat. no. A0452; 1:100 dilution); B cells were identified with anti-CD20 (Beckman-Coulter; cat. no. 1925; 1:50 dilution); macrophages were identified with anti-CD68 (Dako; cat. no. M0876; 1:50 dilution); mast cells were identified with antimast cell tryptase (Abcam; cat. no. ab 2378; 1:50 dilution).

For single immunostaining, after elimination of endogenous peroxidase activity by $3 \% \mathrm{H}_{2} \mathrm{O}_{2}$, sections were preincubated with normal nonimmune serum and then tested by avidin-biotin complex $(\mathrm{ABC})$ using a standard $\mathrm{ABC}$ immunoperoxidase method. Briefly, after washing in Trisphosphate buffered saline (TPBS), $\mathrm{pH}$ 7.6, the sections were incubated with a biotin-labeled secondary antibody, followed by a treatment with $\mathrm{ABC}$ (ELITE ABC, VECTOR PK61000). After washing in TPBS, brown staining was produced by 5 min treatment with 3,3'-diaminobenzidine (DAB). All the incubations were completed at room temperature. Archival lymph node sections were used for positive controls. For negative controls, the first antibodies were omitted or the sections were treated with an immunoglobulin fraction of nonimmune serum as a substitute for the primary antibody. None of the negative control sections showed positive immune staining. Counterstaining was performed with Mayer's hematoxylin.

A computerized quantitative analysis of CD83 expression was carried out at $\times 400$ magnification using the Image-Pro Plus image analysis program (Media Cybernetics, Bethesda, MD, USA). CD83 expression was measured in each section in at least seven randomly selected microscopic fields containing both $\mathrm{CD} 83^{+}$cells and epithelial glands. Statistical compar- ison of expression, measured in pixels per standard microscopic field $\left(0.04 \mathrm{~mm}^{2}\right)$, was performed by $t$ test using Prism $^{\circledR} 5$ (GraphPad Software, San Diego, CA, USA).

Double immunostaining with CD83/CD3 and CD83/ CD20 was used to analyze the possible colocalization of dendritic cells with lymphocytes, using previously reported methods. ${ }^{14,27}$ In brief, after visualization of CD83 with the $\mathrm{ABC}$ substrate kit, sections were washed with $0.1 \mathrm{M}$ glycine-hydrochloric acid buffer, $\mathrm{pH} 2.2$, and then incubated with anti-CD3 or anti-CD20 antibody. After rinsing in TPBS, the sections were incubated with biotinylated secondary antibody and then with alkaline phosphataseconjugated streptavidin (Dako) or with ABC (Dako). A combination of the peroxidase-antiperoxidase (PAP) and alkaline phosphatase-antialkaline phosphatase (APAAP) techniques with antigen visualization with $\mathrm{DAB}$ or Fast Red was also used. Controls were the same as for single immunostaining. Counterstaining was performed with Mayer's hematoxylin.
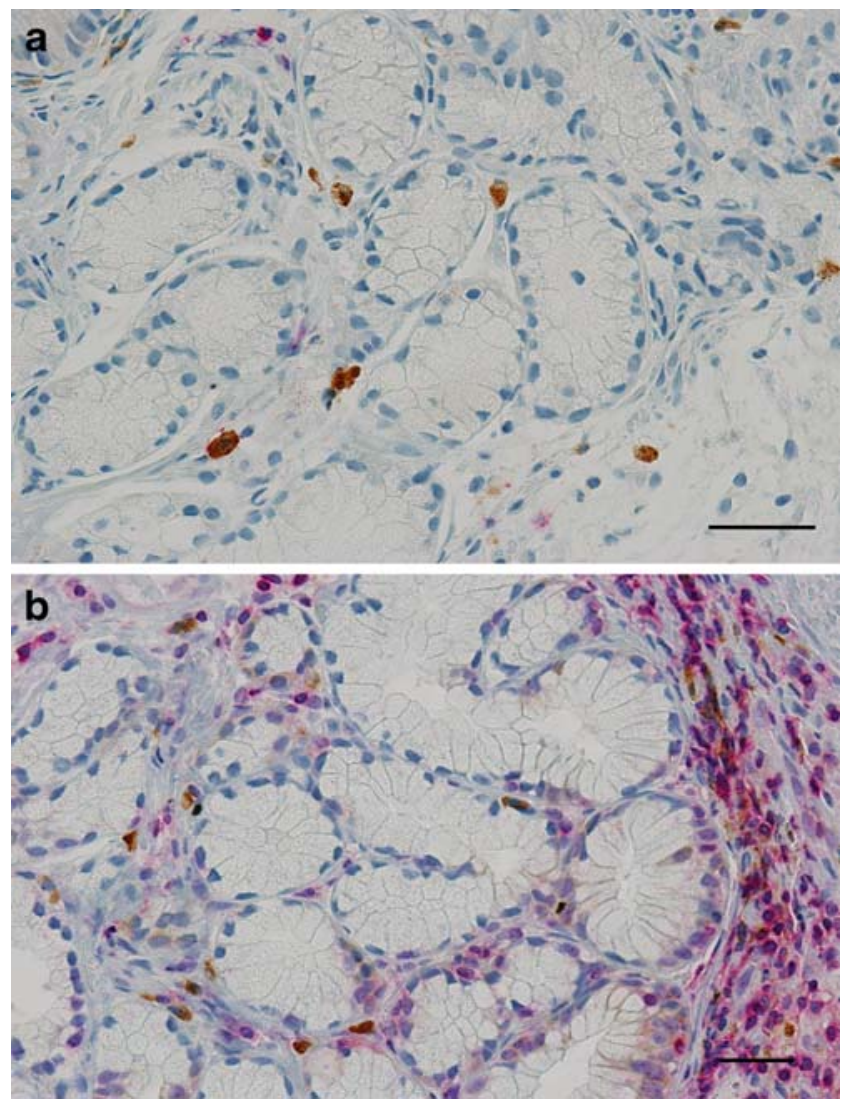

Figure 1 Dendritic cells and T cells in cardiac mucosa in esophageal biopsy specimens showing different degrees of inflammation $(\mathbf{a}, \mathbf{b})$. In $\mathbf{a}$ and $\mathbf{b}, \mathrm{CD} 83$ antigen was visualized using $\mathrm{ABC}$ immunoperoxidase reaction (brown reaction product) while $\mathrm{CD}^{+}$cells were visualized using a Fast Red substrate kit (rose reaction product). Counterstaining with Mayer's hematoxylin. Bars $=50 \mu \mathrm{m}(\mathrm{a}, \mathbf{b})$. 


\section{Electron Microscopy}

Fresh endoscopic biopsy specimens were fixed in $2.5 \%$ glutaraldehyde in $0.1 \mathrm{M}$ sodium cacodylate buffer $(\mathrm{pH}$ 7.4), routinely processed and embedded in Spurr resin. Ultrathin sections were stained with uranyl acetate and lead citrate and examined with the aid of a Morgagni 268D electron microscope. The electron microscopic identification of dendritic cells was carried out according to their distinctive ultrastructural features which include the tubulovesicular system and atypical granules as previously used. ${ }^{14,28}$
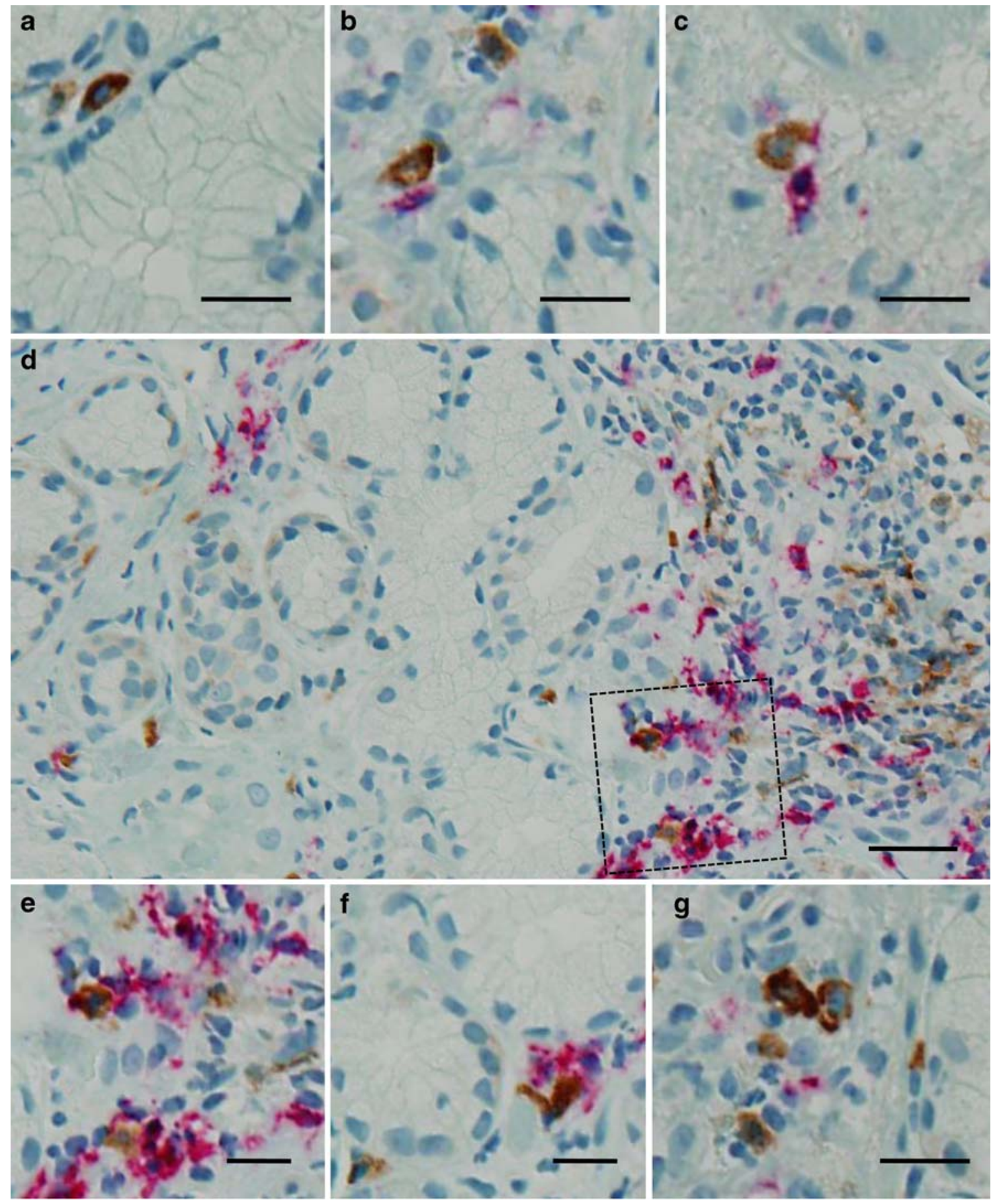

Figure 2 Direct contacts between dendritic cells and lymphocytes in cardiac mucosa (a-g). CD83 antigen was visualized using ABC immunoperoxidase reaction (brown reaction product) $(\mathbf{a}-\mathbf{g})$ while $\mathrm{CD}^{+} \mathrm{T}$ cells $(\mathbf{b}, \mathbf{c})$ and $\mathrm{CD} 20^{+} \mathrm{B}$ cells $(\mathbf{d}-\mathbf{g})$ were visualized using a
Fast Red substrate kit (rose reaction product). Counterstaining with Mayer's hematoxylin. e is a detail of $\mathbf{d}$. $\mathbf{g}$ Dendritic cells contacting each other. Bars $=25 \mu \mathrm{m}(\mathbf{a}-\mathbf{c}, \mathbf{e}-\mathbf{g})$ and $50 \mu \mathrm{m}(\mathbf{d})$. 


\section{Results}

Tissue specimens in which metaplastic intestinal type columnar epithelium was not present contained only cardiac type columnar epithelium consisting of mucous cells. No parietal or chief cells were detected in any of these specimens, and thus, these tissue specimens were identified as cardiac mucosa. According to routine hematoxylin and eosin histology, all 12 cardiac mucosa specimens contained inflammatory cells in the connective matrix surrounding the glands. Immunohistochemistry revealed that immuneinflammatory infiltrates consisted of $\mathrm{T}$ cells $\left(\mathrm{CD}^{+}\right)$, B cells $\left(\mathrm{CD} 20^{+}\right)$, macrophages $\left(\mathrm{CD}^{+} 8^{+}\right)$, and mast cells (mast cell tryptase ${ }^{+}$).
The use of dendritic cell-specific markers, including CD83 and DC-SIGN, demonstrated the presence of dendritic cells in all tissue specimens where they represented a minor cell population (Fig. 1a,b). The degrees of immune inflammation varied markedly between the specimens. Figure 1a,b shows representative images of doubleimmunostained cardiac mucosa specimens in which a difference in the intensity of immune inflammation is readily identifiable. Despite that the intensity of immune inflammation varied markedly in all specimens examined, individually located dendritic cells (Fig. 2a) as well as dendritic cells contacting $\mathrm{T}$ cells were observed in the connective matrix of the cardiac mucosa (Fig. 2b,c). In all specimens, dendritic cells clustering with B cells (Fig. $2 \mathrm{~d}-\mathrm{f}$ )

Figure 3 Electron micrographs showing dendritic cells and their direct contacts with lymphocytes in cardiac mucosa (a-e). In a, d, and $\mathbf{e}$, dendritic cells are marked by large stars while dendritic cell processes are marked by smaller stars (a-d). Arrows in a-d show the tubulovesicular system which is markedly hypertrophied in the cellular processes $(\mathbf{b}, \mathbf{c})$. d A close apposition between a dendritic cell and a lymphocyte-like cell (asterisk). e A contact between a dendritic cell and a plasma cell (asterisk). In d, note hypertrophy of atypical granules in the dendritic cell. Bars $=2 \mu \mathrm{m}$ (a), $1 \mu \mathrm{m}$ $(\mathbf{b}, \mathbf{c}), 5 \mu \mathrm{m}(\mathbf{d})$, and $3 \mu \mathrm{m}(\mathbf{e})$.
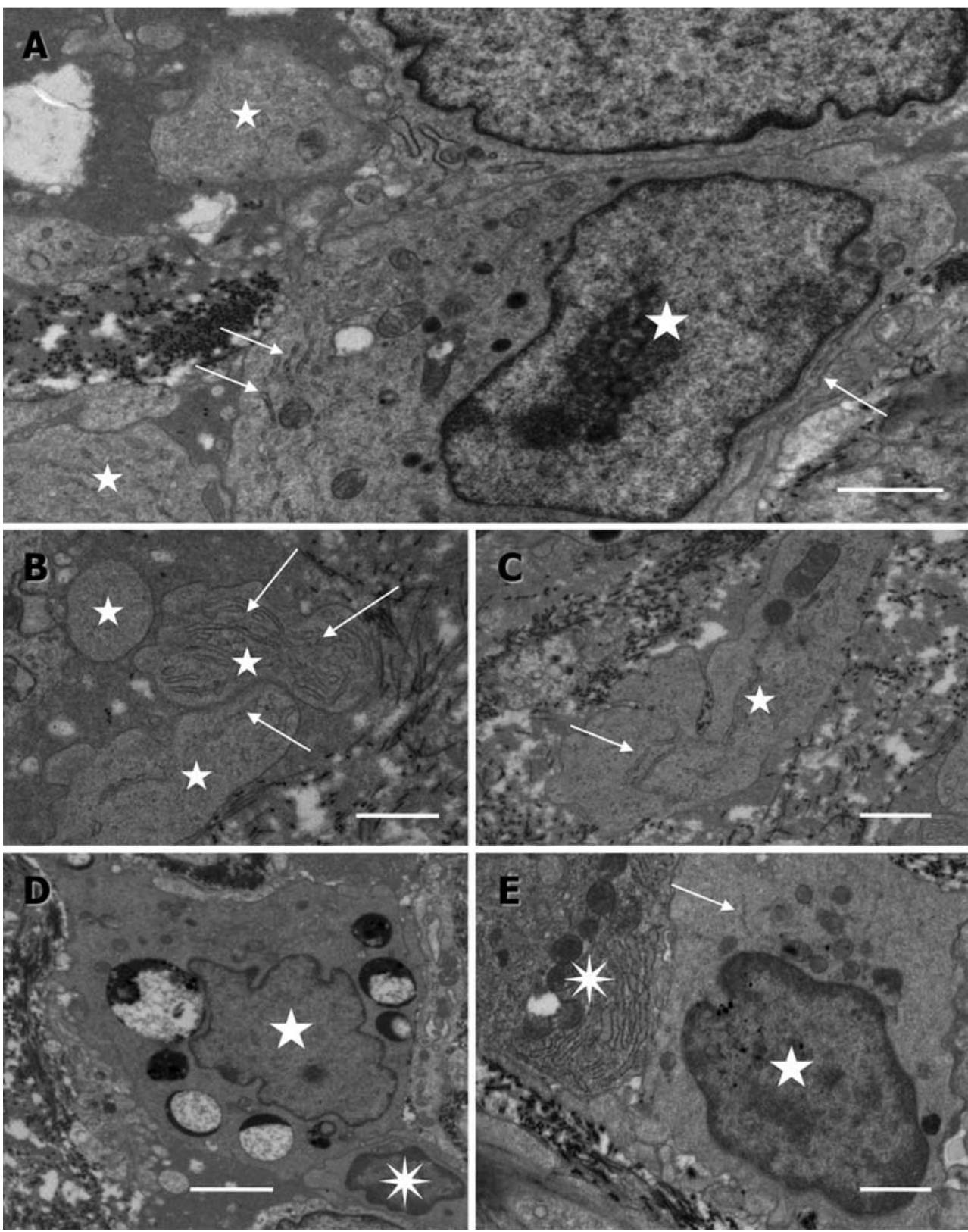
as well as dendritic cells contacting each other (Fig. 2g) were also observed.

Immunohistochemical findings were confirmed by the identification of dendritic cells and their direct contacts with lymphocytes in the cardiac mucosa by electron microscopy (Fig. 3a-e). Cells with the unique ultrastructural features of the dendritic cell family, including the tubulovesicular system and atypical granules, ${ }^{16,28,29}$ were seen in ultrathin sections (Fig. 3a-e). Through cell processes or by direct apposition of cell bodies, dendritic cells formed contacts with lymphocytes (Fig. 3d,e). Cisterns of the tubulovesicular system were usually hypertrophied in dendritic cell processes (Fig. 3a-c) while the hypertrophy of atypical granules occurred predominantly in the perinuclear cytoplasm of dendritic cells (Fig. 3d).

In cardiac mucosa, dendritic cells were found not only in the connective tissue matrix but also along the basal membrane of epithelial cells as well as, in some glands, between mucous cells (Fig. 4a-e). The intensity of the expression of CD83 notably varied between dendritic cells located along the glandular basal membrane (Fig. 4a-e). In the glands, which contained dendritic cells incorporated between mucous cells, the focal accumulations of $T$ cells were also observed (Fig. 4a-e). In these foci, the clustering of dendritic cells with $\mathrm{T}$ cells occurred along the basal membrane (Fig. 4a-e).

Apart from being located in the connective matrix or being associated with the glands, dendritic cells were regularly observed around and within capillaries and microvessels, forming a network in cardiac mucosa. In this location, dendritic cells typically displayed high levels of CD83 expression.

The present study aimed to not only examine the features and patterns of distribution of dendritic cells in cardiac mucosa but also to compare the spatial density of dendritic cells located in the tissue matrix containing cardiac type epithelium-lined glands with the spatial density of dendritic cells located in the tissue matrix containing specialized
Figure 4 Intrusion of dendritic cells and $\mathrm{T}$ cells between mucous cells in cardiac mucosa (a-e). Note contacts between dendritic cells and $\mathrm{T}$ cells along the affected basal membrane, underlying mucous cells $(\mathbf{a}-\mathbf{e})$. Note also various intensities of the expression of CD83 antigen by dendritic cells located along the basal membrane of the glandular epithelial cells $(\mathbf{a}-\mathbf{e})$. In $\mathbf{a}-\mathbf{e}$, CD83 antigen was visualized using $\mathrm{ABC}$ immunoperoxidase reaction (brown reaction product) while $\mathrm{CD}^{+}$cells were visualized using a Fast Red substrate kit (rose reaction product). Counterstaining with Mayer's

hematoxylin. Bars $=25 \mu \mathrm{m}(\mathbf{a}-\mathbf{e})$.
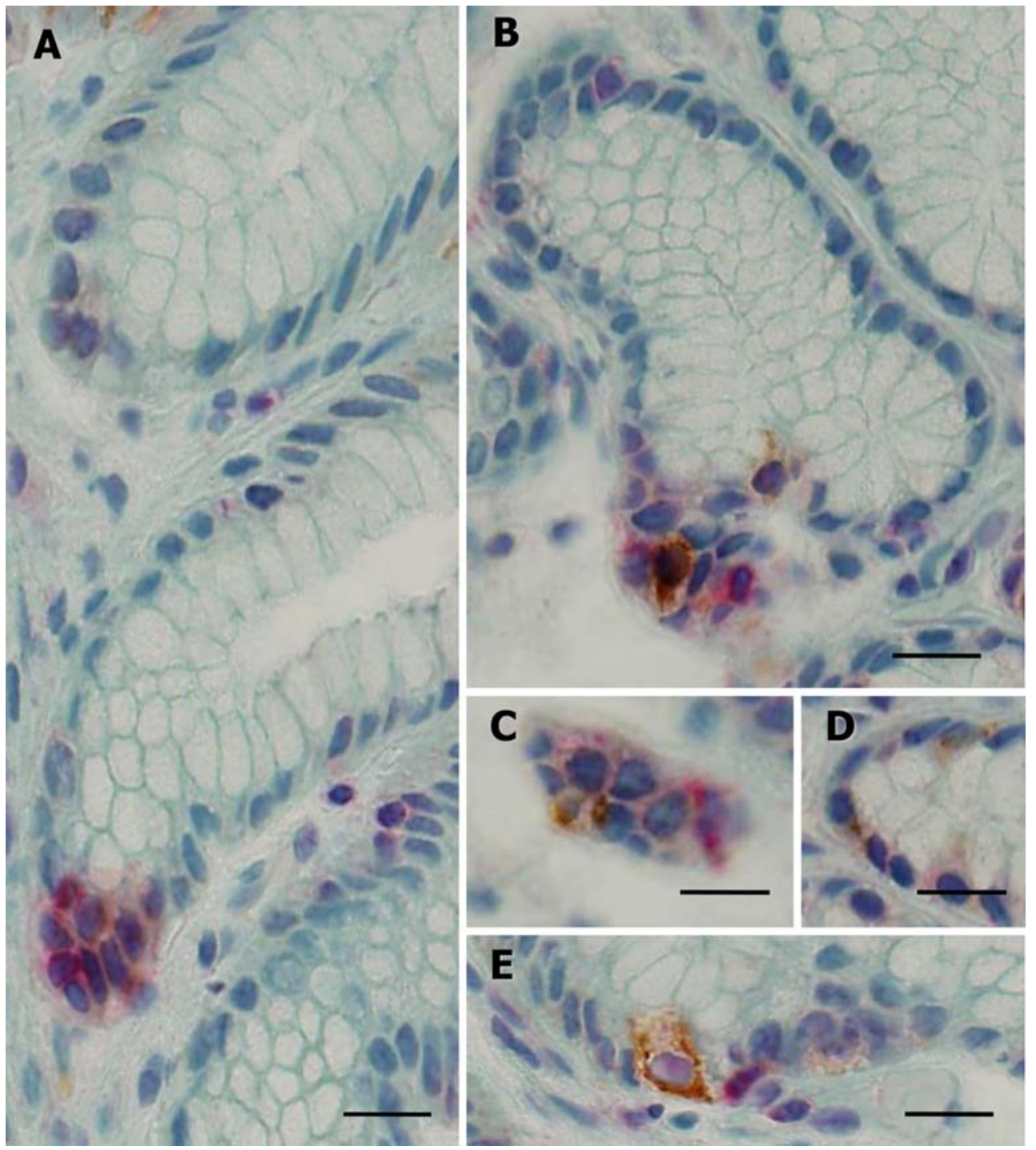
intestinal type epithelium-lined glands in tissue specimens of Barrett's esophagus which contained areas with cardiac mucosa. A semiquantitative analysis indicated that, in these specimens, the numbers of dendritic cells in the connective tissue matrix surrounding cardiac type epithelium-lined glands were greater than the numbers of dendritic cells in the connective tissue matrix that surrounded intestinal type epithelium-lined glands. This was verified by a computerized quantitative analysis of CD83 expression, which found an approximately twofold higher expression of CD83 in cardiac mucosa tissue matrix, compared with that in the Barrett's esophagus connective tissue matrix $(959 \pm 254$ vs $616 \pm$ 172 pixels per standard field; Fig. 5a-c). The distribution patterns of dendritic cells around specialized intestinal type epithelium-lined glands in tissue specimens of Barrett's esophagus corresponded to those described by us earlier. ${ }^{14}$

\section{Discussion}

In agreement with previous notes, ${ }^{2-4}$ this study showed that cardiac mucosa contains an immune-inflammatory cell infiltrate. Immune inflammation was present in all cardiac mucosa tissues examined in the present study, although the degree of inflammatory cell infiltration varied considerably between cardiac mucosa specimens. The immune-inflammatory infiltrates were consistently enriched by dendritic cells, which were present not only around glands in cardiac mucosa but also focally penetrated between glandular mucous cells, suggesting that the integrity of the epithelium in these foci was disrupted. Dendritic cells often formed contacts with both $\mathrm{T}$ cells and $\mathrm{B}$ cells in areas of the affected glandular basal membrane as well as in the connective tissue matrix adjacent to the glands. This could indicate that the activation of some lymphocytes might occur in situ within the mucosa, although the classic pathway for the migration of antigen-loaded dendritic cells through the vascular system to lymphoid organs cannot be excluded, especially as dendritic cells intensely expressing CD83 antigen were observed around and within capillaries and microvessels.

The intensity of the expression of CD83, a marker of dendritic cell maturation, ${ }^{21-24}$ varied between the cells in cardiac mucosa, but dendritic cells that were in contact with lymphocytes typically displayed high levels of CD83 expression. Supporting the possibility that some dendritic cells were activated cells, electron microscopy revealed a marked hypertrophy of atypical granules and cisterns of the tubulovesicular system, both of which are known to represent structures involved in antigen-presenting functions of dendritic cells. ${ }^{16,17}$

An intriguing and potentially important finding of this study was that focal aggregations of dendritic cells and dendritic cells contacting each other were identified in the tissue matrix of cardiac mucosa. Clustering of dendritic cells with each other is known to occur in a number of autoimmune diseases ${ }^{16,17,30}$ and has not been described in any disease in which autoimmune mechanisms are not involved. We, therefore, speculate that the immune inflam-
Figure 5 Dendritic cells in Barrett's esophagus tissue specimens containing both cardiac type epithelium (a, c) and specialized intestinal type epithelium $(\mathbf{b}, \mathbf{c})$. $\mathbf{a}$ and $\mathbf{b}$ Single ABC immunostaining of tissue slides showing the presence of dendritic cells (brown) in the lamina propria surrounding two different types of glands. Counterstaining with Mayer's hematoxylin. Bars= $100 \mu \mathrm{m}(\mathbf{a}, \mathbf{b})$. c Expression of CD83 antigen in cardiac mucosa $(C M)$ and in specialized intestinal type mucosa of Barrett's esophagus $(B E)$, evaluated as the number of pixels per standard field using a computerized quantitative analysis (see the "Material and Methods" section).
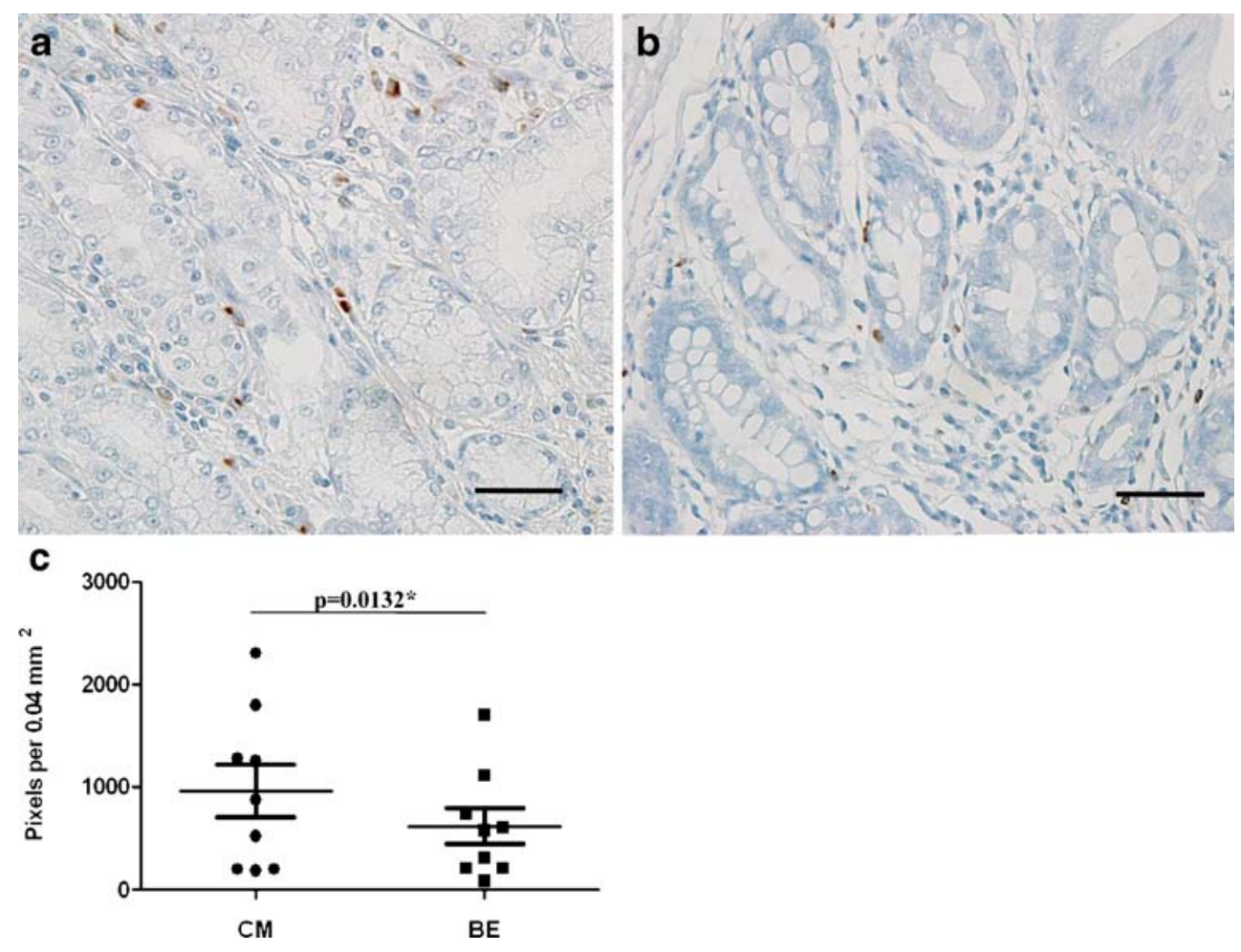
mation observed in cardiac mucosa might represent an ongoing autoimmune reaction or that autoimmune mechanisms are at least involved. The finding of dendritic cells penetrating into glands and closely apposed to glandular mucous cells also supports this possibility. Further studies are needed to evaluate the possible role of recruitment of autoimmune mechanisms in the formation of both cardiac type metaplasia and Barrett's esophagus.

Perhaps surprisingly, there were more dendritic cells in the connective tissue matrix surrounding cardiac type epitheliumlined glands compared to intestinal type epithelium-lined glands in the specimens which contained both cardiac mucosa and Barrett's intestinal metaplasia. This was confirmed by measuring the expression of CD83 antigen by dendritic cells, which was significantly higher in cardiac mucosa compared to intestinal metaplasia.

Overall, this study's findings suggest that the individual's immune response to ongoing exposure to noxious luminal contents may have a role in both the development of cardiac mucosa and its replacement by Barrett's esophagus. The importance of cardiac mucosa as the possible precursor lesion to Barrett's esophagus is indicated by studies showing similar protein expression profiles for both cardiac mucosa and Barrett's esophagus, including the expression of the small intestine marker proteins sucraseisomaltase and crypt cell antigen, and DAS-1, a marker of specialized columnar mucosa. ${ }^{31-34}$ Compelling evidence has also been provided by studies that found cardiac mucosa developing in the cervical remnant esophagus after esophagectomy, an in vivo human model for de novo reflux disease. ${ }^{3,35}$ In one such study, ${ }^{35}$ intestinal metaplasia developed in some patients with adenocarcinoma subsequently arising in one protein expression features. The specific cellular and molecular mechanistic events that induce change from cardiac mucosa to Barrett's esophagus are unknown ${ }^{1-8,35-37}$ but the reduced inflammation in intestinalized mucosa compared to cardiac mucosa, shown in the present study, supports the teleological argument that intestinal metaplasia develops to protect the esophagus against the inflammation induced by injurious components of the refluxate. ${ }^{2}$ The role of immune mechanisms, and possibly autoimmune mechanisms, in the neglected cardiac mucosa and in the formation of Barrett's esophagus requires further evaluation.

The present study is the first to report the presence of dendritic cells in cardiac mucosa. There is an ever-increasing body of data on the use of dendritic cells in immune therapeutic approaches against cancers and autoimmune diseases. ${ }^{38-41}$ The finding of dendritic cells in cardiac type metaplasia might have a practical implication.

Acknowledgements We thank the National Health and Medical Research Council, Cancer Institute NSW, NSW Cancer Council, and St. Vincent's Clinic Foundation, Sydney for the financial support.
Open Access This article is distributed under the terms of the Creative Commons Attribution Noncommercial License which permits any noncommercial use, distribution, and reproduction in any medium, provided the original author(s) and source are credited.

\section{References}

1. Lord RVN. History and definition of Barrett's esophagus. In Yeo CJ, Dempsey DT, Klein AS, Pemberton JH, Peters JH, eds. Shackelford's surgery of alimentary tract, 6th ed. Philadelphia: Saunders Elsevier, 2007, pp 334-340.

2. DeMeester SR, DeMeester TR. Columnar mucosa and intestinal metaplasia of the esophagus: fifty years of controversy. Ann Surg 2000;231:303-321. doi:10.1097/00000658-200003000-00003.

3. Der R, Tsao-Wei DD, DeMeester T et al. Carditis: a manifestation of gastroesophageal reflux disease. Am J Surg Pathol 2001;25:245-252. doi:10.1097/00000478-200102000-00013.

4. Oberg S, Peters JH, DeMeester TR et al. Inflammation and specialized intestinal metaplasia of cardiac mucosa is a manifestation of gastroesophageal reflux disease. Ann Surg 1997;226:522-532. doi:10.1097/00000658-199710000-00013.

5. Chandrasoma P. Pathophysiology of Barrett's esophagus. Semin Thorac Cardiovasc Surg 1997;9:270-278.

6. Lord RV. Genetic Basis of the Barrett's metaplasia, dysplasia, Adenocarcinoma sequence. Probl Gen Surg 2001;18:53-70. doi:10.1097/00013452-200106000-00008.

7. Kerkhof M, Kusters JG, van Dekken H, Kuipers EJ, Siersema PD. Biomarkers for risk stratification of neoplastic progression in Barrett esophagus. Cell Oncol 2007;29:507-517.

8. Quinlan JM, Colleypriest BJ, Farrant M, Tosh D. Epithelial metaplasia and the development of cancer. Biochim Biophys Acta 2007;1776:10-21.

9. Mantovani A, Allavena P, Sica A, Balkwill F. Cancer-related inflammation. Nature 2008;454:436-444. doi:10.1038/nature07205.

10. O'Byrne KJ, Dalgleish AG. Chronic immune activation and inflammation as the cause of malignancy. $\mathrm{Br} \mathrm{J}$ Cancer 2001;85:473-483. doi:10.1054/bjoc.2001.1943.

11. Macarthur M, Hold GL, El-Omar EM. Inflammation and cancer. II. Role of chronic inflammation and cytokine gene polymorphisms in the pathogenesis of gastrointestinal malignancy. Am J Physiol Gastrointest Liver Physiol 2004;286:G515-G520. doi:10.1152/ajpgi.00475.2003.

12. Moons LM, Kusters JG, Bultman E et al. Barrett's oesophagus is characterized by a predominantly humoral inflammatory response. J Pathol 2005;207:269-276. doi:10.1002/path.1847.

13. Cappello F, Rappa F, Anzalone R, La Rocca G, Zummo G. CD1a expression by Barrett's metaplasia of gastric type may help to predict its evolution towards cancer. Br J Cancer 2005;92:888890. doi:10.1038/sj.bjc.6602415.

14. Bobryshev YV, Tran D, Killingsworth MC, Buckland M, Lord RV. Dendritic cells in Barrett's esophagus and esophageal adenocarcinoma. J Gastrointest Surg 2008;in press.

15. Banchereau J, Steinman RM. Dendritic cells and control of immunity. Nature 1998;392:245-252. doi:10.1038/32588.

16. Lotze MT, Thomson AW. Dendritic cells: biology and clinical applications. 2nd ed. San Diego, CA: Academic, 2001.

17. Lipscomb MF, Masten BJ. Dendritic cells: immune regulators in health and disease. Physiol Rev 2002;82:97-130.

18. Heath WR, Belz GT, Behrens GM et al. Cross-presentation, dendritic cell subsets, and the generation of immunity to cellular antigens. Immunol Rev 2004;199:9-26. doi:10.1111/j.0105-2896.2004.00142.x.

19. Steinman RM, Banchereau J. Taking dendritic cells into medicine. Nature 2007;449:419-426. doi:10.1038/nature06175. 
20. Berchtold S, Mühl-Zürbes P, Maczek E, Golka A, Schuler G, Steinkasserer A. Cloning and characterization of the promoter region of the human CD83 gene. Immunobiology 2002;205:231246. doi:10.1078/0171-2985-00128.

21. Lechmann M, Zinser E, Golka A, Steinkasserer A. Role of CD83 in the immunomodulation of dendritic cells. Int Arch Allergy Immunol 2002;129:113-118. doi:10.1159/000065883.

22. Breloer M, Kretschmer B, Lüthje K et al. CD83 is a regulator of murine B cell function in vivo. Eur J Immunol 2007;37:634-648. doi:10.1002/eji.200636852.

23. Fujimoto Y, Tu L, Miller AS et al. CD83 expression influences $\mathrm{CD}^{+} \mathrm{T}$ cell development in the thymus. Cell 2002;108:755-767. doi:10.1016/S0092-8674(02)00673-6.

24. Lechmann M, Krooshoop DJ, Dudziak D et al. The extracellular domain of CD83 inhibits dendritic cell-mediated T cell stimulation and binds to a ligand on dendritic cells. J Exp Med 2001;194:1813-1821. doi:10.1084/jem.194.12.1813.

25. Geijtenbeek TB, Torensma R, van Vliet SJ et al. Identification of DC-SIGN, a novel dendritic cell-specific ICAM-3 receptor that supports primary immune responses. Cell 2000;100:575-585. doi:10.1016/S0092-8674(00)80693-5.

26. Engering A, Geijtenbeek TB, van Vliet SJ et al. The dendritic cellspecific adhesion receptor DC-SIGN internalizes antigen for presentation to T cells. J Immunol 2002;168:2118-2126.

27. Bobryshev YV, Lord RS. Mapping of vascular dendritic cells in atherosclerotic arteries suggests their involvement in local immuneinflammatory reactions. Cardiovasc Res 1998;37:799-810. doi:10.1016/S0008-6363(97)00229-0.

28. Bobryshev YV, Lord RSA. Ultrastructural recognition of cells with dendritic cell morphology in human aortic intima. Contacting interactions of vascular dendritic cells in athero-resistant and athero-prone areas of the normal aorta. Arch Histol Cytol 1995;58:307-322. doi:10.1679/aohc.58.307.

29. Takahashi K, Naito M, Shultz LD, Hayashi S, Nishikawa S. Differentiation of dendritic cell populations in macrophage colony-stimulating factor-deficient mice homozygous for the osteopetrosis (op) mutation. J Leukoc Biol 1993;53:19-28.

30. Bobryshev YV. Dendritic cells in atherosclerosis: current status of the problem and clinical relevance. Eur Heart J 2005;26:17001704. doi:10.1093/eurheartj/ehi282.
31. Mendes de Almeida JC, Chaves P, Pereira AD, Altorki NK. Is Barrett's esophagus the precursor of most adenocarcinomas of the esophagus and cardia? A biochemical study. Ann Surg 1997;226:725-735. doi:10.1097/00000658-199712000-00009.

32. Griffel L, Weston A, Karalnik N, Amenta P, Das K. Early diagnosis of short-segment Barrett's esophagus (SSBE) using an immunohistochemical marker: an inter-institutional blinded study. Gastroenterology 1998;114:A140.

33. Groisman GM, Amar M, Meir A. Expression of the intestinal marker $\mathrm{Cdx} 2$ in the columnar-lined esophagus with and without intestinal (Barrett's) metaplasia. Mod Pathol 2004;17:1282-1288. doi:10.1038/modpathol.3800182.

34. DeMeester SR, Wickramasinghe KS, Lord RV et al. Cytokeratin and DAS-1 immunostaining reveal similarities among cardiac mucosa, CIM, and Barrett's esophagus. Am J Gastroenterol 2002;97:2514-2523. doi:10.1111/j.1572-0241.2002.06033.x.

35. Lord RV, Wickramasinghe K, Johansson JJ, DeMeester SR, Brabender J, DeMeester TR. Cardiac mucosa in the remnant esophagus after esophagectomy is an acquired epithelium with Barrett's-like features. Surgery 2004;136:633-640. doi:10.1016/j.surg.2004.01.009.

36. Goldblum JR. Barrett's esophagus and Barrett's-related dysplasia. Mod Pathol 2003;16:316-324. doi:10.1097/01.MP.0000062996.66432.12.

37. Chandrasoma P, Wickramasinghe K, Ma Y, DeMeester T. Is intestinal metaplasia a necessary precursor lesion for adenocarcinomas of the distal esophagus, gastroesophageal junction and gastric cardia? Dis Esophagus 2007;20:36-41. doi:10.1111/ j.1442-2050.2007.00638.x.

38. Shu S, Zheng R, Lee WT, Cohen PA. Immunogenicity of dendritic-tumor fusion hybrids and their utility in cancer immunotherapy. Crit Rev Immunol 2007;27:463-483.

39. Fujii $\mathrm{S}$. Exploiting dendritic cells and natural killer $\mathrm{T}$ cells in immunotherapy against malignancies. Trends Immunol 2008;29:242-249. doi:10.1016/j.it.2008.02.002.

40. Vulink A, Radford KJ, Melief C, Hart DN. Dendritic cells in cancer immunotherapy. Adv Cancer Res 2008;99:363-407. doi:10.1016/S0065-230X(07)99006-5.

41. Duivenvoorde LM, van Mierlo GJ, Boonman ZF, Toes RE. Dendritic cells: vehicles for tolerance induction and prevention of autoimmune diseases. Immunobiology 2006;211:627-632. doi:10.1016/j.imbio.2006.05.014. 